\title{
Building the UK vision of a driverless future: $A$ Parliamentary Inquiry case study
}

\author{
Chris Tennant (10 ${ }^{1,2 \otimes}$, Susan Howard ${ }^{3} \&$ Sally Stares (D) $^{4}$
}

The UK Government has endorsed the case for autonomous vehicle (AV) technology and its economic benefits in its industrial strategies since 2013. In late 2016 the Science and Technology Committee in the House of Lords (the legislature's upper chamber) conducted an Inquiry into the policy. We conduct a content analysis of the text corpus of the Inquiry. Drawing from theories of sociotechnical change we explore how it contributes to building a vision of a future $\mathrm{AV}$ world embedded in a national economic and technological project. The technology is framed as a solution to societal grand challenges and the Inquiry corpus is dominated by actors committed to the project. Alternative visions, including sceptical interpretations, are present in the corpus, but rare, reflecting the selection process for contributions to the Inquiry. Predominantly, the corpus represents the public as deficient: dangerous drivers, unaware of promised benefits and unduly anxious about the unfamiliar. Their views are marginal in this Parliamentary Inquiry's findings. AV technology is one of several possible means to pursue wider mobility policy goals of greater safety, affordability, access and sustainability. Our analysis suggests that the pursuit of an AV future risks becoming a goal in itself instead of a means to these broader societal goals.

\footnotetext{
${ }^{1}$ London School of Economics and Political Science, London, UK. ${ }^{2}$ University College London, London, UK. ${ }^{3}$ Independent researcher, London, UK. ${ }^{4}$ City, University of London, London, UK. 凶email: c.j.tennant@lse.ac.uk
} 


\section{Introduction}

ntroducing new technologies such as autonomous vehicles $(\mathrm{AVs})^{1}$ has social impact and since the 1990s there have been growing calls for innovation to be democratised within the field of science and technology studies (Ely et al., 2014; Stilgoe et al., 2014). Yet despite public doubts (e.g. European Commission, 2015, 2020; Tennant et al., 2019) governments have expressed strong commitment to roll out AV technology and hailed its transformative potential (e.g. Centre for Connected and Autonomous Vehicles, 2016; U.S. Department of Transportation, 2016). The empirical work of this paper examines one particular step within the development of AV technology in the UK by analysing the UK House of Lords Science and Technology Committee's Inquiry into AVs, for which hearings were held during November 2016. We draw upon theories of sociotechnical change and ask how the different participants in the inquiry, and the inquiry process itself, contribute to building a vision of an $\mathrm{AV}$ future.

The UK Government stated its intention to pave the way for driverless cars in its 'National Infrastructure Plan 2013' (HM Treasury, 2013), initiating a process of consultation and planning; results were announced in February 2015. The Government's accompanying press release was headlined 'UK to lead development of driverless car technology' and announced a 'green light' for testing of driverless technology on UK Roads (Department for Business Skills and Innovation, and Department for Transport, 2015). A code of practice followed for testing AVs (Department for Transport, 2015a) and by late 2017 the technology had become a keen plank of the mobility strategy that comprised the response to one of four 'grand challenges' within the Government's overall industrial strategy and modernising vision (HM Government, 2017). To support developments the UK government sponsored prototypes and trials through a dedicated unit, the Centre for Connected and Autonomous Vehicles (CCAV). Governments in other countries have progressed similar plans to enable the technology (Hottentot et al., 2015).

The presumed benefits of the technology include improved safety; reduced congestion and faster journeys; widened mobility access and efficiency gains, such as improved distribution logistics (all from Centre for Connected and Autonomous Vehicles, 2016, p. 5), as well as reduced pollution (coupled with vehicle electrification, HM Government, 2017, p. 48); reallocation of driving time to other activities (Department for Transport and Jones, 2016); and finally, industrial opportunities for the UK (HM Government, 2017, p. 49).

Similar benefits are claimed in US Government documents (e.g. U.S. Department of Transportation, 2016, 2017). These perceived opportunities are used to justify government resolve to facilitate the introduction of AVs to the road. In the UK, Hopkins and Schwanen (2018) have documented the extent to which such Government determination generates an aura of inevitability around the technology. Innovators and governments assert that this inevitability justifies hastening the technology's advent (e.g. McGoogan, 2016). The inevitability makes it pointless to resist; the safety case makes it immoral (Sparrow and Howard, 2017).

\section{Imagining the future}

Over the last ten years there have been repeated claims that mobility will be revolutionised by driverless technology, with far reaching societal transformations (Burns and Shulgan, 2018; The Economist, 2016, 2018). This continues a tradition of futuristic visioning of vehicle transportation well exemplified by General Motor's Futurama exhibition at the 1939 New York World Fair. Building technologies of the future requires a vision or blueprint of that future first. This paper uses a case study to consider whether and how such a vision is being built in the UK.
Scholars have begun to document how the developers of AV technology, and governments supportive of its deployment, are building such visions. For example, Graf and Sonnberger (2019) conducted a qualitative content analysis of 22 position papers from German stakeholders on AV technology: they focused their analysis on the role of users in future visions of autonomous driving, or in what Jasanoff and Kim (2009) term the sociotechnical imaginary. Haugland and Skjølsvold (2020) conducted a content analysis of consultation responses to draft legislation in Norway together with a case study of a pilot deployment, highlighting, inter alia, how public consultation and public pilot testing encourage expectations of the possible benefits of the new technology. Mladenovic et al. (2020) conducted an analysis of policy documents in three different countries: Finland, the UK and Germany. They applied a theory-based analytical framework drawing on the concepts of sociotechnical imaginaries and governance cultures to reveal similarities and differences between the visions being developed in each country. They too considered how these visions positioned the public as users rather than citizens. Manderscheid (2018) analysed videos and promotional material associated with two visions of automobility offered by Google and Mercedes-Benz, applying Akrich's (1992) concept of sociotechnical scripts to explore representations of users who are no longer drivers within visions of a future still targeting economic growth and increased automobility.

Among the various theoretical concepts that are deployed to capture visions of AV futures, Braun and Randell (2020, p. 1) argue for the utility of the theory of sociotechnical imaginaries, stating:

"The visions surrounding "self-driving" or "autonomous" vehicles are an exemplary instance of a sociotechnical imaginary: visions of a future technology that has yet to be developed or is in the process of development.'

Jasanoff and Kim (2009, p. 120) originally defined sociotechnical imaginaries as

'collectively imagined forms of social life and social order reflected in the design and fulfilment of nation-specific scientific and/or technological projects.'

A key feature of this definition is that imaginaries are built around nation-specific projects, and three of the four studies mentioned above locate the visions they analyse in national contexts. In the UK, AVs were positioned as part of the 'Future of Mobility' Grand Challenge (HM Government, 2017). In so doing, the UK Government follows a trend towards framing the relationship between technology and society as one of meeting societal challenges (Kaldewey, 2018) and seeks to legitimise the technology as a societal project, mobilising heterogeneous actors to meet the challenge (Kuhlmann and Rip, 2018). Framing technologies as responses to Grand Challenges rhetorically establishes a vision for the imagined future (Flink and Kaldewey, 2018), realising Jasanoff's (2015, p. 19) further definition of imaginaries as 'collectively held and performed visions of desirable futures'. Shared beliefs and representations play a central role in the development and sustenance of shared identities: Moscovici's theory of social representations (Farr and Moscovici, 1984) provides an account of how shared visions can be performed in practice, for example through group engagement within a shared project (Bauer and Gaskell, 1999, 2008) such as national grand challenges.

These theoretical concepts have been used to critique the framing of national technological projects. The rhetoric of challenges encourages what van Loon (2002) calls a 'politics of urgency'; the rhetoric of being in a race (Kaldewey, 2018) 
legitimises sociotechnical solutions (Flink and Kaldewey, 2018), so that technologies are offered as instrumental solutions to identified societal problems (Savaget and Acero, 2017). The desirability of the goals, such as improved safety or reduced pollution, is appropriated by the solution, presenting itself as logically necessary and inevitable. Framed thus, it might be expected that social appraisal exercises such as parliamentary inquiries risk seeking to justify proposed solutions, to perform a normative democratic engagement (Stilgoe et al., 2014) and to close rather than open debate (Stirling, 2008). In such a process, commitment to the grand project tends to treat users as passive subjects (Welsh and Wynne, 2013). Critics of such approaches to technological progress argue for the public to be involved as citizens integral to the co-production of sociotechnical systems (Sovacool and Hess, 2017) within a framework of responsible innovation (Stilgoe et al., 2013).

Visions of an AV future also position the public as a customer exercising rational choices rather than as a citizen (Graf and Sonnberger, 2019; Mladenović et al., 2020). This continues the way the public are typically positioned in transport policy-making (Bergman et al., 2017), and encourages the reasoning that public rejection of the technology must be explained as based on ignorance or upon irrational fears, whether in the case of AVs (Graf and Sonnberger, 2019), or more generally (Sturgis and Allum, 2004; Welsh and Wynne, 2013). Elite imaginaries promoting technological solutions to social problems marginalise public perspectives (Smallman, 2019). This can be seen in examples of public $\mathrm{AV}$ demonstrations and tests where it has been argued that their performative purposes require so controlled an environment that learning opportunities are limited, and failure criteria are ill-defined or not defined at all (Engels et al., 2019).

When the public are framed as future customers, visionbuilding seeks to recruit members of the public by selling the benefits of the new technology. Pangbourne et al (2020) document how visions of driverless 'mobility as a service' promise to resolve the social dilemmas generated by aggregate individual transport demand while ignoring the logic that continuing commercial imperatives must perpetuate increasing aggregate demand. Hildebrand (2019, p.158) shows how AV promotional materials' address the [technological] sublime and overcome its dialectics in their visual rhetoric and myth-making' by promising just enough emancipation from the constraints of the existing system without exposure to darker possibilities, presenting the 'awe-inspiring' but not the 'awful'. Solving the problems of the present, representations of the new and unfamiliar are thereby anchored in understandings of the familiar-as described in theories of social representations (Moscovici, 1984):

'A vanguard vision is more likely to gain traction if it is tied to entities and expectations familiar enough to provide an intelligible guide to the imagined future' (Hilgartner, 2015, p. 40).

Across this range of related but distinct conceptual frameworks that theorise sociotechnical change (Sovacool and Hess, 2017) there are common themes around vision-building, the development of representations of the technology, the existing society within which it is to fit, and the future society it is intended to build. The literature leads us to expect key stakeholders to build a persuasive vision of AVs as a solution to national grand challenges, to mobilise resources. To examine a case of such visionbuilding, we approached the analysis of a UK parliamentary inquiry as an exploratory exercise, leaving open precisely how such visions or representations should be conceptualised. After reflecting upon implications of how the Inquiry was framed and who contributed, we identify the main themes present in the corpus and then ask the following questions:
RQ1. Which themes are more and less prevalent-overall, and for different types of contributors?

RQ2. In the corpus, do we find the following elements, that our literature review suggests are likely to be present in the building of expectations or an imaginary:

RQ2a. The development of AVs being presented as a national project?

RQ2b. Presentation of AV development as inevitable?

RQ2c. More emphasis or content on benefits than on risks?

RQ2d. Representations of the public as passive, and to be persuaded?

\section{Method}

A case study. Following Sovacool and Hess (2017) we carry out a content analysis of the material relating to a single case study. Such an analysis can reveal the different expectations for the technology expressed by participants in the Inquiry and can address the question of whether the Inquiry process itself contributes to building a particular representation of an AV future. We have generated both a quantitative and a qualitative analysis of the corpus material. The quantitative analysis is the primary tool for answering RQ1. RQ2 is mostly addressed with qualitative, interpretative analysis, illustrated with selected quotations from the corpus, and with links drawn where relevant to the quantitative results as well as to external sources.

We examine the case of 'Driverless vehicles-where are we going?', a 2016 Inquiry by the House of Lords Science and Technology Committee. It followed closely after an inquiry carried out earlier by CCAV. UK parliamentary inquiries are intended to inform Government strategy. Typically conducted to analyse national crises, or to plan development (particularly for transport), they are sometimes expected to fulfil a role of keeping Government accountable. In practice the aims, and outcomes, of inquiries are more complex, for example in sustaining the authority of policy makers and their agendas (Rough, 2011). The Inquiry was run by the staff to the committee, who advertised to invite evidence, but also retained a list of likely key stakeholders for any issue and contacted these specifically. Those contributing written evidence include members of the public but most of the $85^{2}$ authors of written evidence and 20 individual witnesses giving oral evidence contributed because of their role as stakeholders, many of them committed to the technology ${ }^{3}$.

Supplementary Table S1 lists the documents comprising the corpus, from the formal call for evidence (September 2016) through the evidence itself to the final report (March 2017) and the Government response (October 2017). This information is summarised in Table 2 at the start of our findings. The documents are available on the Inquiry website ${ }^{4}$.

For the purpose of this analysis, each text unit is a paragraph, and the distribution of units is shown across 14 different categories of contributor in Table 2. Our analysis does not include consideration of material on marine, agricultural and other 'nonroad' AVs: we focussed solely on the material directly related to road vehicles, a total of 3350 out of the 4109 text units.

Analytic procedure. We use classical content analysis (CA) to address the corpus. CA can code latent or manifest meanings; our coding frame leans toward the latter as we intend our analysis to be as transparent as possible without stating the obvious. However, we do go beyond simply counting instances of words or phrases, instead classifying 'words, sentences and larger text units $\ldots$ as exemplars of predefined themes and valuations' (Bauer, 2000 , p. 134). We developed a coding frame initially based on an open reading of the corpus. After several iterations we established a reliable code book: intercoder reliability on documents coded 
independently was good, with Cohen's Kappa co-efficient for a sample of 61 text units calculated as 0.70 . This is essentially a test of agreement for all codes across these 61 units or $3843^{5}$ possible codings. Cohen's Kappa is considered to correct too strongly for chance agreement (Gwet, 2008; Wongpakaran et al., 2013) in analyses such as ours, where most of the sampled units were not marked by either coder as having most of the 3843 codes present; Gwet's $\mathrm{AC}_{1}$ coefficient (Riffe et al., 2019) was calculated as 0.92. These steps taken to achieve a reliable coding scheme were necessary to enable us to make claims about the nature of the content in the corpus such as relative prevalence and cooccurrence of themes (Krippendorff, 2004).

We next divided the corpus between the two coders separately applying this coding frame. Coders first identified the presence or absence of a broad theme, then the presence or absence of particular subsidiary code (sub-code) themes. If the broad theme was present but no sub-theme, a catch-all 'unspecified' sub-code was applied. Two instances of this merit further comment: firstly, 'economic models not specified' included many references to the topic of insurance as an allocation of costs and liabilities. Secondly, 'innovators not specified' captures many references to $\mathrm{AV}$ development organisations, and automotive companies, that neither related to the three specified Innovator topics, nor merited identification as a separate topic. The codebook of 64 codes and their presence across the corpus (108 documents and 3350 text units) is summarised in Table 1 . The content analysis was managed using the Nvivo software programme, and we applied Nvivo's analytical tools such as automatic word search coding, co-occurrence analysis and basic descriptive statistical analysis to aid the process of coding as well as analysing the coding results and qualitatively interpreting the texts.

\section{Findings}

In this section we begin by setting our analysis in context, reporting on how the Inquiry was formally framed and who its contributors were. We then go on to report our content analysis, first giving a quantitative overview of the prevalence and distribution of themes, and then offering a broadly qualitative and more interpretative analysis, drawing links to further details of our quantitative analysis, and to the broader literature where relevant.

Framing. The original call for evidence provides a clear agenda:

'The Government aims to ensure that the UK is a world leader in developing, testing and deploying connected and autonomous vehicles and, as set out above, has been proactive in its response. This Inquiry will examine whether the actions taken by the Government are appropriate, considering both the scale of economic opportunity and the potential public good benefits (House of Lords Science and Technology Select Committee, 2016, p. 2)'.

While the Inquiry exercise provides the scope for competing visions or expectations to be expressed, this framing presumes the deployment of AVs to be desirable. Framed thus, the Inquiry materials seem to reinforce the expectations or imaginary of AV technology projected by the UK Government, as a response to the 'grand challenge' of future mobility. The call for evidence listed 18 questions which are provided as Supplementary Table S2. Although these questions cover both potential benefits and negative impacts of AV technology, many questions ask what is needed to create an enabling environment for its introduction. Most contributors broaden their responses to cover additional issues they consider important, as they are invited to do in the call for evidence.
The contributors. Supplementary Table S1 listing the documents in the corpus identifies all of the contributors of written evidence. Table 2 summarises the contributions, identifying the amount of the corpus contributed by each.

The consultation process led to the inclusion of a particular set of voices, establishing what and who this data can be said to represent. This corpus also cannot be said to reflect all 'AV stakeholders'. For example, several of the commercial businesses contributing are very small, while no major automotive manufacturers contributed. Immediately prior to the Inquiry period (September-December 2016) CCAV called for evidence addressing the development of a testing ecosystem within the UK (Centre for Connected and Autonomous Vehicles, 2017). Nineteen of the 53 contributors to this CCAV Inquiry were commercial organisations, including General Motors, Nissan and Jaguar Land Rover. Despite different Inquiry briefs, it seems likely that some participants chose not to duplicate the process of giving evidence.

A key feature of the corpus is that many contributors' activities concerning AVs are in some form funded by the Government. These range from ministers from Government departments to social science academics involved in human factors work or critical responses drawing on work from science and technology studies. 12 of the 85 contributors of written evidence are representatives of Government departments or agencies. Of the eight oral sessions, one is devoted to non-road AVs, and of the remaining seven, witnesses in two (sessions 1 and 8 ) are exclusively representatives of Government departments, in another (session 5) the witnesses are two local government representatives and in another (session 4) representatives from local government or Government-funded AV trials.

To some extent therefore, the Inquiry records a conversation between different branches of Government or entities otherwise committed by the Government to the project of bringing AV technology to the road. This is not unusual: Government's efforts flow through several different entities, including its own Innovate UK agency which oversees the Transport Systems Catapult (merged into the Connected Places Catapult in April 2019), as well as the newly created CCAV, which itself has created a separate offshoot, Zenzic, to manage AV testing. These entities collaborate and provide research reports to each other (e.g. BSI and Transport Systems Catapult, 2017; Transport Systems Catapult, 2017). The Inquiry process itself is a dialogue between the UK's upper chamber and the Government. It is in effect a closed collaboration, rather than an open public dialogue of the kind realised in engagement activities (Stilgoe et al., 2014).

Prevalence and distribution of themes-quantitative analysisRQ1. Table 3 shows the concentration of the major themes, as identified by the percentage of text units coded with the headcodes, within each class of contributor. The reader should note that because each text unit was a paragraph (usually a few sentences), most text units covered several themes and thus had more than one code applied to them-so percentage figures sum to more than 100 across the rows.

Participant focus reflects the different roles: insurers focus on economic models, which as noted earlier includes allocation of costs and liabilities; consumer groups, charities and members of the public emphasise the public as a topic, while Government actors highlight the role of regulation and regulators. With respect to our research questions, we make two initial observations: first, Government actors pay less attention to the public than other participants do; second, against expectation, possible risks feature in more of the corpus than possible gains: we discuss this further below. 


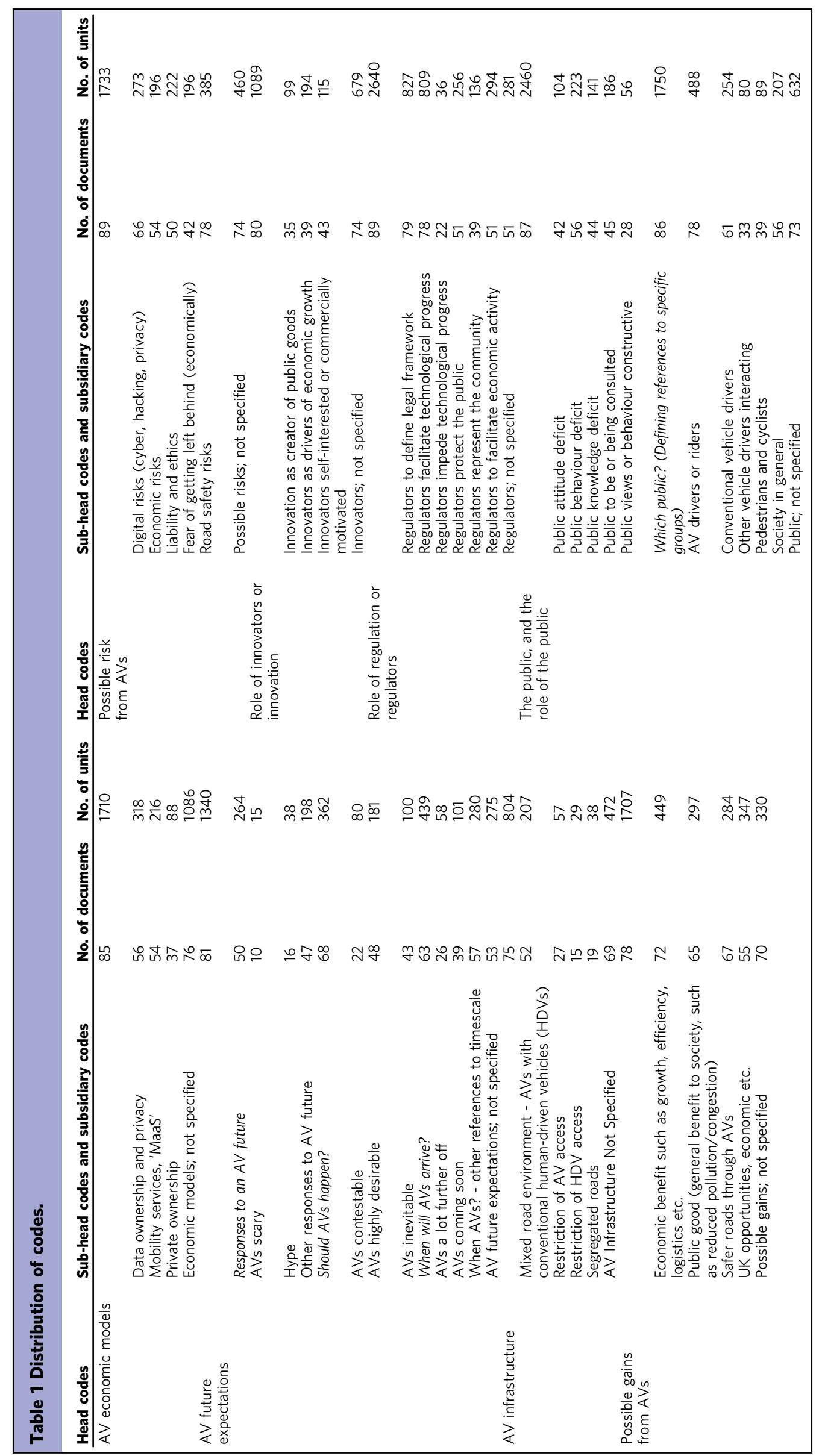




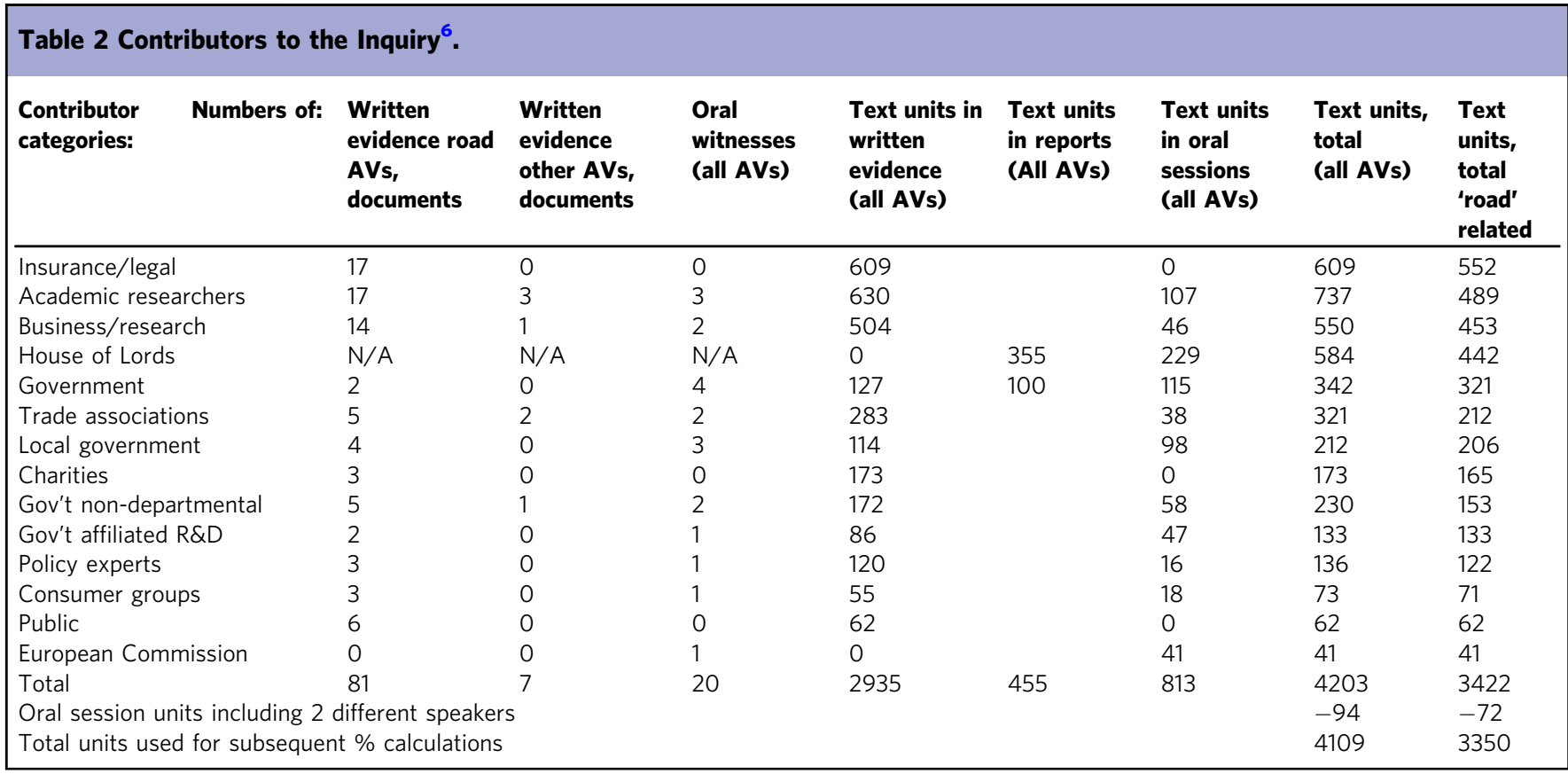

Table 3 Distribution of major themes (head codes) within categories of contributors.

\begin{tabular}{|c|c|c|c|c|c|c|c|c|c|c|}
\hline \multirow[t]{2}{*}{ Class of contributor } & \multirow[b]{2}{*}{$\mathrm{N}$} & \multirow[b]{2}{*}{$\begin{array}{l}\text { Percent } \\
\text { of } \\
\text { corpus }\end{array}$} & \multirow{2}{*}{$\begin{array}{l}\text { AV } \\
\text { Economic } \\
\text { models }\end{array}$} & \multirow{2}{*}{$\begin{array}{l}\text { AV } \\
\text { future } \\
\text { expect- } \\
\text { ations }\end{array}$} & \multirow{2}{*}{$\begin{array}{l}\text { AV } \\
\text { infra- } \\
\text { structure }\end{array}$} & \multirow{2}{*}{$\begin{array}{l}\text { Possible } \\
\text { gains } \\
\text { from } \\
\text { AVs }\end{array}$} & \multirow{2}{*}{$\begin{array}{l}\text { Possible } \\
\text { risk } \\
\text { from } \\
A V_{s}\end{array}$} & \multirow{2}{*}{$\begin{array}{l}\text { Role of } \\
\text { innovators, } \\
\text { innovation }\end{array}$} & \multirow{2}{*}{$\begin{array}{l}\text { Role of } \\
\text { regulation, } \\
\text { regulators }\end{array}$} & \multirow{2}{*}{$\begin{array}{l}\text { The } \\
\text { public }\end{array}$} \\
\hline & & & & & & & & & & \\
\hline Insurance/legal & 552 & 16 & 54 & 23 & 10 & 19 & 45 & 19 & 56 & 40 \\
\hline Academic Research & 489 & 14 & 44 & 25 & 13 & 21 & 30 & 23 & 49 & 48 \\
\hline Business/research & 453 & 13 & 48 & 27 & 24 & 42 & 44 & 43 & 48 & 41 \\
\hline House of Lords & 442 & 13 & 40 & 41 & 26 & 36 & 53 & 36 & 64 & 36 \\
\hline HM Government & 321 & 9 & 50 & 39 & 21 & 51 & 47 & 45 & 78 & 29 \\
\hline Trade Association & 212 & 6 & 54 & 33 & 42 & 45 & 39 & 38 & 48 & 42 \\
\hline Local government & 206 & 6 & 32 & 34 & 25 & 29 & 21 & 26 & 51 & 28 \\
\hline Charity & 165 & 5 & 30 & 40 & 22 & 41 & 51 & 24 & 39 & 67 \\
\hline $\begin{array}{l}\text { HMG non } \\
\text { departmental }\end{array}$ & 153 & 4 & 32 & 23 & 29 & 40 & 32 & 35 & 41 & 35 \\
\hline HMG affiliated R\&D & 133 & 4 & 41 & 24 & 19 & 29 & 40 & 35 & 37 & 29 \\
\hline Policy Expert & 122 & 4 & 38 & 35 & 23 & 46 & 44 & 16 & 19 & 60 \\
\hline Consumer Group & 71 & 2 & 37 & 30 & 34 & 31 & 65 & 23 & 45 & 63 \\
\hline Public & 62 & 2 & 15 & 32 & 13 & 39 & 35 & 10 & 15 & 56 \\
\hline European & & & & & & & & & & \\
\hline Commission & 41 & 1 & 20 & 12 & 7 & 20 & 15 & 12 & 29 & 20 \\
\hline $\begin{array}{l}\text { Total Percent of } \\
\text { corpus }(\mathrm{N}=3,350)\end{array}$ & & 100 & 44 & 30 & 21 & 34 & 42 & 30 & 51 & 41 \\
\hline
\end{tabular}

Figure $1^{7}$ shows the most prevalent detailed themes, as identified by the subsidiary codes listed in Table 1 . Many of the dominant themes in Fig. 1-the three regulator themes $(1,2,9)$, economic benefits (4) and UK opportunities (6)-combine together to represent the Governmental project of building an $\mathrm{AV}$ future in the UK to deliver economic growth and progress.
Several topics, such as the question of liabilities and ethics (7), data ownership (8) and digital (security) risks (13) are often, as we discuss later, treated as challenges to be resolved to reach the desired goal. Public goods (10) such as reduced congestion and pollution, and safer roads (12) are both core expectations of the beneficial outcomes of AVs as identified in the introduction. Two 


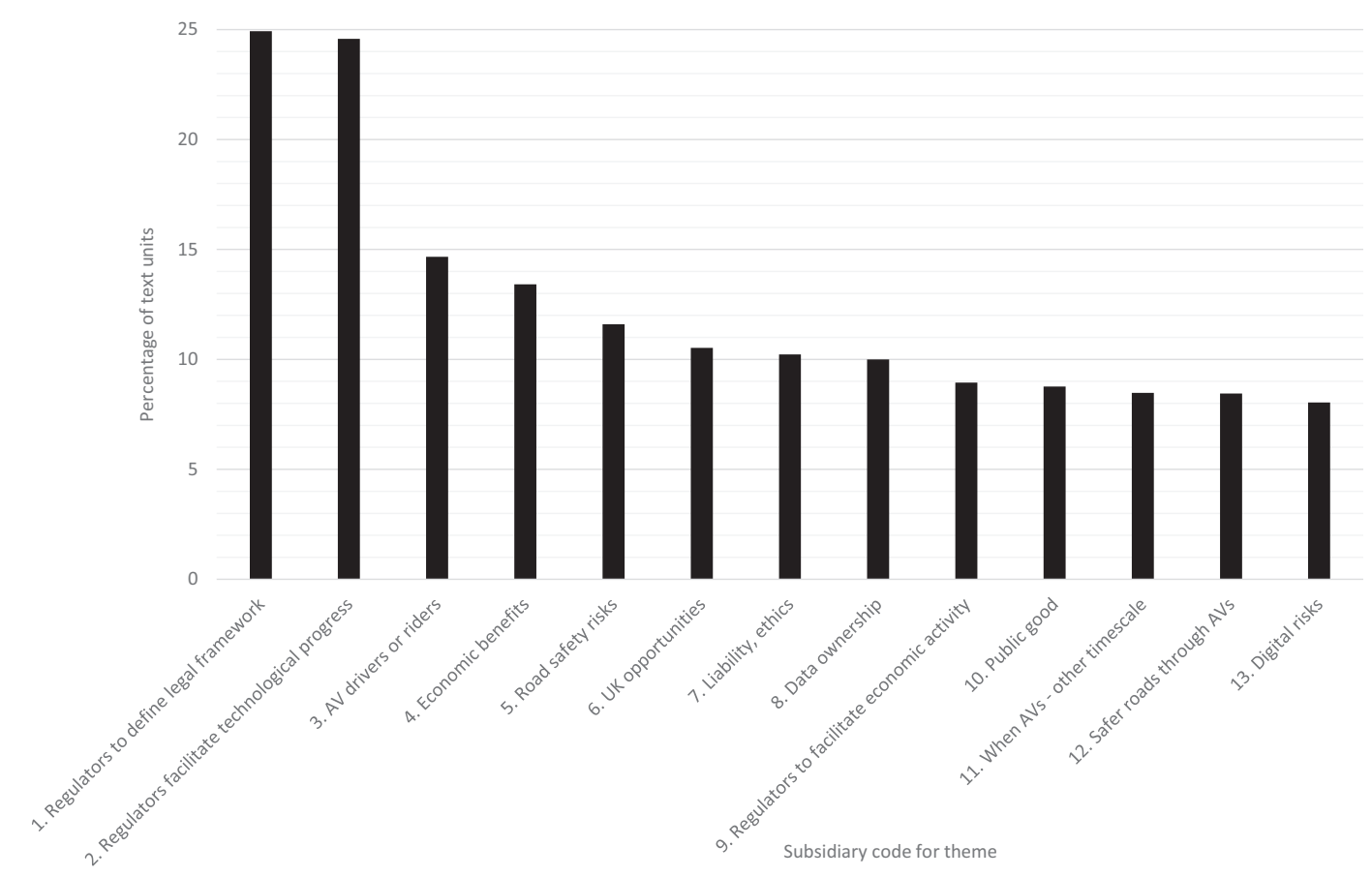

Fig. 1 Most prevalent detailed themes (subsidiary codes) observed for all contributors.

of the most prevalent themes are integral components of the debate: AV drivers or riders (3) captures any reference to members of the public as future users of AV technology, while road safety risks (5) references possible new road safety risks arising from the technology. Lastly, the topic of when AVs (11) hints at the impatience of many participants, particularly Governmental actors, for whom the question 'when can we expect AV technology on the roads?' is pressing.

Figure 2 gives another more granular picture of how subsidiary codes were distributed among contributors, focusing on the six participant groups contributing the largest number of text units (which represent $71 \%$ of the corpus). For simplicity of presentation, rather than present one figure for each of the eight head codes, we have grouped them into four: Fig. 2a represents the role of innovators/innovation and the role of regulation/ regulators; Fig. $2 \mathrm{~b}$ represents the public and the role of the public; Fig. $2 \mathrm{c}$ represents possible gains from AVs and possible risks from $\mathrm{AVs}$; and Fig. 2d represents future expectations and infrastructure as well as AV economic models. Each quarter of the figure relates to groups of related codes, each bar represents a contributor group. The blocks within the bars give the percentage of the group's text units that were coded with each of the subsidiary codes. We included codes present in more than $5 \%$ of the group's text ${ }^{8}$, so for example, in Fig. $2 \mathrm{~d}$ the absence of any of 'The public' subsidiary codes from the HMG column does not mean the Government never mentions the public, just that codes related to the public are not dominant themes in the Government material. To maximise the legibility of the charts we use different ranges on their vertical axes.

We noted that the Inquiry's framing strongly influences the content: within the 'Regulators and Innovators' codes the prevalence of regulator roles as defining the legal framework and facilitating technological progress reflects the purpose of the Inquiry, to examine whether the Government was doing enough in both of those areas. Alternative frames, such as the Government controlling technology and commercial actors, or prioritising a holistic vision of the transport system, are rarely used. Within each of the Figure quadrant, we would highlight a few key results.

In Figure 2a, the need to define legal frameworks (often insurance regimes) to enable the technology, and the role of regulators in driving technological progress, and (for Government and business actors) economic activity, dominates. Regulators 'representing the community' or 'protecting the public' when mentioned by Government entities are often limited to expectations of delivering safer roads with AV technology. Innovators and the role of innovation receive little mention - the role of innovation is not problematised by the Inquiry.

Figure $2 \mathrm{~b}$ suggests that for the Inquiry the public's role is to be future AV drivers or riders, or to justify the need for AVs because of the 'public behaviour deficit' of bad driving by existing road users. Academic contributors-a heterogeneous group including both technology academics and social scientists - and local Government both consider the topic in the context of society as a whole: but the most striking feature of the Figure is the lack of attention to the public from the Government's contribution to the Inquiry.

Figure $2 \mathrm{c}$ indicates that for the Government and House of Lords, the AV future offers economic benefit and opportunity for the UK; the risks comprise the question of attribution of insurance liabilities as an issue to be resolved. Other actors contribute to the building of expectations of an AV future by rehearsing the public good benefits (see Introduction) and also treating risks as issues to be resolved. Business contributors emphasise the need not to be left behind.

Figure $2 \mathrm{~d}$ aggregates three different major themes: economic models, AV future expectations, and Infrastructure. Infrastructure receives limited attention in the Inquiry beyond debates over what a road environment mixing conventional and automated vehicles could or should look like. We suggest that this relative lack of interest in practical (versus regulatory) and potentially expensive Government action stems from the Inquiry's focus on vision-building ahead of any on-the-ground deployment. Local government and business contributors both pay attention to mobility service business models, while the Lords, business and 

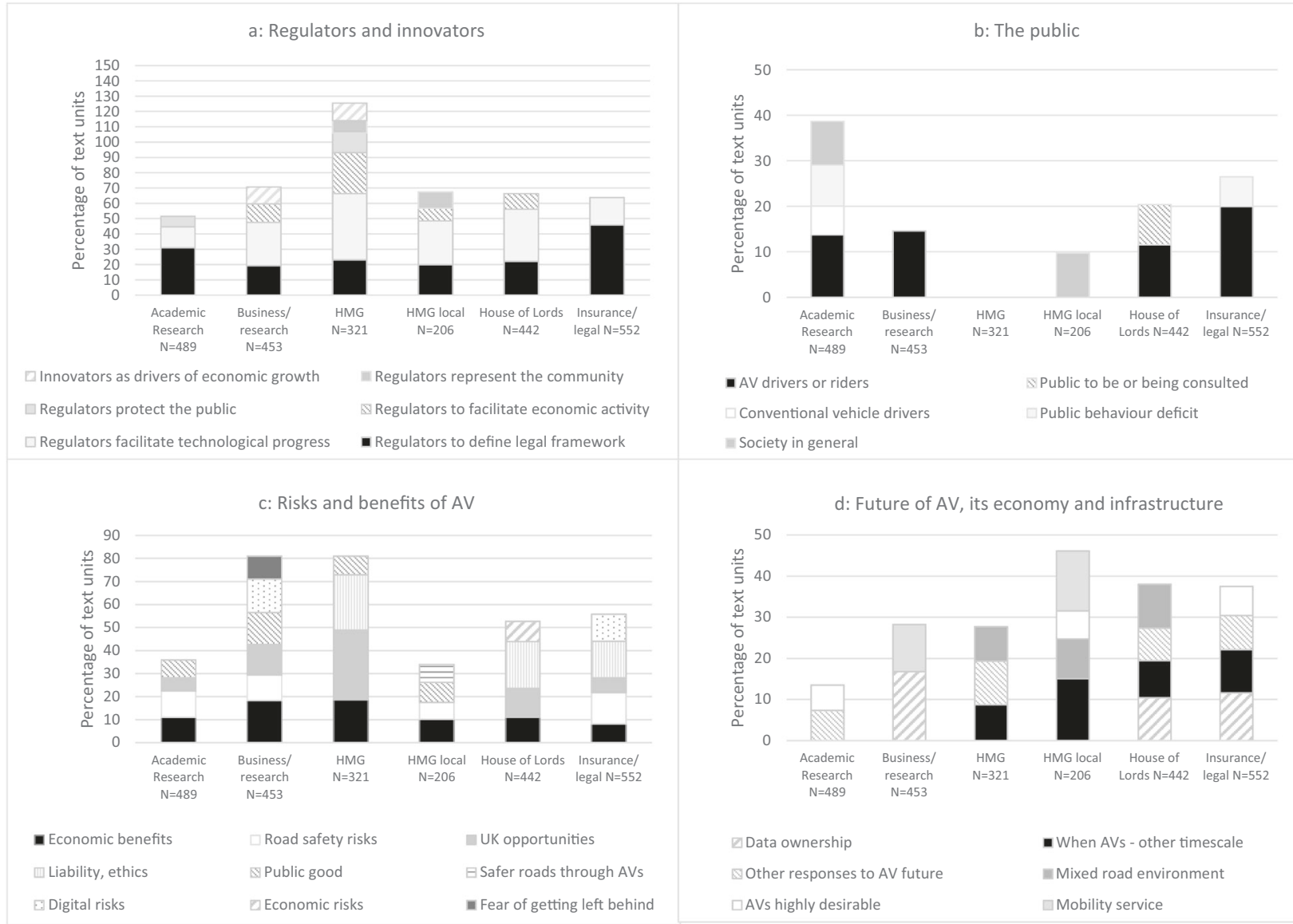

Fig. 2 Most mentioned detailed themes (subsidiary codes) for top 6 classes of contributor.

legal contributors emphasise data ownership concerns. Assertions that the $\mathrm{AV}$ future is desirable dominate.

\section{Qualitative analysis}

RQ2a: The National Project. The Government's own principal objective here is to facilitate, and participate in, technological progress:

'The Government is keen to ensure we make the most of the opportunities they offer, and has established the Centre for Connected and Autonomous Vehicles (CCAV) to keep the UK at the forefront of the development and deployment of this technology.' (Government, 78, paragraph $2^{9}$ )

For other participants in the Inquiry, the imperative for regulation to define the legal framework within which AVs are to operate dominates, frequently because this is considered the first issue on the critical path to facilitate progress. This is often linked to providing the legal framework to manage liabilities, a focus of the Government and insurance/legal contributors. Others focus on cybersecurity (e.g. Orbit City Lab 3, Razorsecure 16) and data ownership (e.g. Aviva 24, Deloitte 42, Information Commissioner's Office 61) as hurdles to overcome. Government also emphasises opportunities for the UK economy and the role of Government in facilitating economic activity. Commercial ('business/research') and professional ('insurance/legal') participants frame risks as obstacles to be tackled in order to achieve the objective of introducing the technology, not as reasons to reshape the objective or to slow down progress. The engineering consultant Atkins, a participant in some of the UK's AV trials, provides an example:
'Transportation plays a critical role in society and as such should be safe by design across the planning and execution of new roads and railways [...] a cyber secure framework that puts transportation at its centre must be created and an organisational culture change that creates defined cyber security elements within its operations.' (Atkins, 44, paragraph 8)

Atkins also frames the data needs of AV technology as an opportunity to achieve UK leadership:

'The UK can be a world leader in establishing a market focused independent data exchange role that allows for data from all providers to be handled in an anonymous way that drives value creation as well as network optimisation.' (ibid paragraph 8)

Few contributors challenge the Government to reflect on what the objectives are beyond expediting the introduction of the technology and achieving a leading role for the UK: exceptions include two academic critiques from researchers drawing on science and technology studies (Hopkins, 19, quoted later in this article; Cohen and Cavoli, 65, referenced below).

The Government seeks to transform the present, defined by 'Human error [as] a factor in up to $94 \%$ per cent of all recorded road injury collisions in Great Britain' (Government, 78, para 14):

'Connected vehicles that can talk to each other, and to the roadside infrastructure, are the future. We want the UK to embrace these technologies which will transform our roads and open up a brand new route for global investment. The potential for transformation is significant, and vehicle to infrastructure and vehicle to vehicle communications will 
enable safer road conditions for users.' (Government, 88, paragraph 7)

The Government also seeks wider benefits than safer roads and opportunities to attract inward investment such as 'productivity, efficiency and accessibility' (Government, 98, paragraph 23).

These abstract policy goals echo the list drawn from earlier Government statements (see Introduction). The promotion of the technology, and its entrenchment in UK Industrial Strategy (HM Government, 2017), is therefore unsurprising; what is noticeable within the Inquiry corpus is how others share the task of building and corroborating this vision. Fifteen pieces of written evidence refer to the majority of collisions being at least partially attributable to human error, usually stating $94 \%$ or a similar figure, with several referencing the Government's 2015 pathway document for this (Department for Transport, 2015b). This is often treated as a case for AVs, and Jasanoff and Kim (2009) argue that such repetitions contribute to establishing the discursive frames that are then filtered into the dominant targets for policy. But as Cohen and Cavoli point out in their literature review (Cohen et al., 2017) and in their written evidence, the logical step from 'human error [partly] responsible for over $94 \%$ of crashes' to 'removing human drivers will greatly improve safety' obscures the complexities of moving from the present road environment to a distant future without human drivers.

Many contributors of written evidence anticipate the same benefits from AV technology besides safety: economic efficiencies through fuel savings, release of driving time for productive activity and improved logistics as well as public goods such as wider access to mobility and reduced congestion and emissions. Emphasising the opportunities, eight describe them as 'transfor$\mathrm{m}$ [ative]' and ten as 'huge' or 'enormous'.

In the oral evidence, demand and supply sides of this imaginary are personified by the Government's two witnesses. The Minister for Transport's opening statement describes the Government's job as providing the regulatory framework to ensure that a self-interested private sector delivers to society the many benefits the technology offers, and plans for their impact upon society. Alongside him, the Minister for Business, Energy and Industrial Strategy sees the task as ensuring that that private sector treats the UK as a 'go-to destination', positioning AVs within an industrial strategy aimed at 'tackling the imbalances of prosperity and productivity across the country' (96, Q63). The hope expressed is that the technology provides a catalyst for re-engineering society. The UK Atomic Energy Authority also hopes for a social transformation on the labour supply side:

'This is potentially an opportunity to 'rebalance the economy' if we can encourage more of our talent to focus on STEM subjects. We need to imagine a society in which digital professionals are the highest paid and the most valued by society as a whole.' (30, p. 3 )

At the same time, SmarterUK, a trade representative body for the technology sector, imagines a social transformation on the demand side:

'The deployment of autonomous vehicles will lead to shift in how we view public and private transport. Not only will it enable greater mobility for those groups within society who currently have limited options; such as children, the elderly, and the disabled, increasing the welfare of these demographics; but it will also lead to a shift in business and delivery models, with citizens, particularly in urban areas, moving towards ownership models driven by the sharing economy.' (82, p. 1)
RQ2b: A desirable, inevitable future, and RQ2c: the balance of benefits and risks. This is not to say that participants in the Inquiry don't see risks. Table 3 shows a greater weight of content dealing with risks than benefits of the technology. But risks are framed as issues to be addressed rather than challenges to the imaginary. Only $10 \%$ of the corpus addresses whether AVs should happen. But most of this content implies that AVs are highly desirable $(5 \%)$ or inevitable (3\%) while only $2 \%$ suggests that the desirability of AVs might be contestable. In only $1 \%$ did we find suggestions that the technology might be over-hyped. Engineering consultancy Atkins exemplifies how the desirability and necessity of pursuing an AV future is taken for granted:

'It is increasingly important that the UK leads the charge in demonstrating its capabilities in a growing and nationally important market that will facilitate productivity and maintain the attractiveness and competitiveness of Britain's economy'. (Atkins, 44, paragraph 10)

Specialist witnesses are sought by the Committee to explain how they see the technology evolving, so there are frequent statements that take for granted the emergence of the technology:

'In one hundred years time we will be using autonomous vehicles. It seems unimaginable that we will not have the computers, sensor and software to solve the remaining challenges. We can see an end state.' (UK Atomic Energy Authority, 30, p. 1)

Instead of the question of whether, or how, the technology might be desirable, Government participants and the Lords concentrate on timescales, the question of 'how soon?' Timescale is discussed in $12 \%$ of the corpus: grand challenges are often perceived as a race (Kaldewey, 2018) and there is a fear of being left behind (Fig. 2b).

The $2 \%$ of content challenging this future consists of 80 text units: 9 of these are posed in two written submissions that draw on science and technology studies perspectives, 16 are from members of the public, and 15 from a policy expert critiquing the logic of the safety argument. However, these views do gain the Committee's attention: 15 more of the references are to be found in the oral sessions, with a further 6 in their final report. The final report contains fewer assertions of the desirability of the technology than flagging of issues, emphasising two particular concerns: first, problems associated with Level 3 autonomy, especially the likely dangers of over-trust in the technology; second, 'The eradication, or near eradication, of human error will only be realised with full automation. $C A V$ are not the only way to reduce road casualties. There are other means by which to achieve this and we urge the Government not to lose sight of these other possibilities.' (97, paragraph 87)

Committee member Lord Hennessy of Nympsfield, selfdescribed 'sceptic', worries that the selectivity of the Inquiry process determines the nature of the vision it builds:

'... it seems to me that the possibility of having mixed fleets of non-, highly, and fully automated vehicles all operating at the same time raises the possibility of chaos on a truly heroic scale. I wonder if your modelling will look at the worst cases, because there is a danger [...] by the very nature of this Inquiry, that we will attract as witnesses evangelists for the future, which we are all very keen on but you can be slightly gung-ho. There is a slight sound of the tambourine being rattled sometimes.' (93, Q45) 
R2d Modelling the public. We noted above the repetition of the argument for AVs based on the deficiencies of human driving. Contributors also tend to find the public at fault for their responses to driverless vehicles, either as ignorant of their benefits, thus deficient in knowledge, or as deficient in attitude in their resistance to new technology. Insurer Ageas captures both:

'The public need to be educated on the different types of autonomous vehicles and the benefits of using them. Large scale trials, such as Volvo's Drive Me London scheme, are likely to prove critical in explaining to the man in the street what autonomous cars are likely be capable of, where they will operate, and what the individual and societal benefits are. We envisage that increasing understanding will lead to more favourable attitudes towards autonomous vehicles and drive up their adoption.' (39, paragraph 4.1)

Several contributors point out that the public have little exposure to the technology, which encouraged the head of CCAV to set aside public concerns in his oral evidence:

'You have to take all these surveys with a little pinch of salt. That famous saying by Henry Ford: if he had asked what people wanted they would have said a faster horse ${ }^{10}$. People have not yet properly interacted with this technology.' (89, Q5)

Although there are frequent (186) references to the public being consulted or involved in demonstration projects, this is often to increase public acceptance, not to help to shape the vision:

'Therefore, we see research exploring how potential customers will interact with this new technology as essential to achieving acceptance.' (Transport for Greater Manchester, 25, p. 2)

This is coherent with the perceived imperative of introducing the technology. However, it reinforces the founding premise (of driver error) that the public is a problem. Likewise instead of engaging with the possibility that Level 3 automation, where the driver has to remain ready to resume control, may be intrinsically too dangerous, contributors often locate the problem not with the system but with the driver, who will need to be educated about the capabilities of different systems, e.g.:

'.public education and awareness raising initiatives will be needed to help drivers understand the distinction between the different levels of autonomous technology. A crucial message is that until truly fully autonomous vehicles are available, the driver must be fully alert and ready to assume control at all times, and is legally responsible for any accidents that occur.' (RoSPA, 23 paragraph 19)

Systems-based human factors work (e.g. Bainbridge, 1983; Leveson, 2011) argues that failure is located in the complete system, not simply the operator: Level $3 \mathrm{AVs}$ are frequently criticised as unsafe systems (for the public debate, see Solon, 2018). If Level 5 automation becomes commonplace, actors used to seeing the public as problematic may readily consider them to be obstructive: although detailed implementation of this further future receives less attention in the corpus, some written contributors (e.g. Deloitte, 42; Ageas, 39; SmarterUK, 82) anticipate geofencing or other forms of restriction on human drivers on the road network, while others such as the Motorcycle Action Group (68) worry about the exclusion of some road users from AV domains just as the conventional car drove pedestrians from parts of the road network (Norton, 2008).

We comment further on two salient aspects that emerge across the answers to our research questions: first, how obstacles to an
AV future are treated, with specific reference to the Inquiry report, and second the concern over regulation stifling innovation.

Obstacles to an AV future, as identified in the Inquiry report. Our quantitative analysis justifies the conclusion that the overwhelming weight of the corpus serves to build the vision of an inevitable, desirable AV future that will itself contribute to building a better, more prosperous UK society. But the Lords do heed concerns raised in the Inquiry. For example they acknowledge the problems with transfers of control in Level 3 vehicles (97, p. 35f) and issues associated with a mixed fleet (97, p. 36f). They flag these as needing further research. Other concerns, such as the difficulty of attributing liability $(97$, p. 22f) for insurance purposes, or the lack of technical skills in the UK are treated as threshold issues to be resolved by Government action. Similarly, the risks that a system embedded in the original system of automobility and framed by commercial pressures may struggle to improve accessibility (97, p. 26f) or congestion (p. 29f) are raised, but there are no suggestions for their mitigation beyond a generic call for the 'right policy decisions' (p. 30). This underplays the likelihood that the wrong policy decisions may achieve the opposite of these intended benefits (Cohen and Cavoli, 2019).

On the subject of the economic costs and benefits of UK investment in AVs, the report argues that 'There is little hard evidence' (p. 32) and calls for more analysis before concluding:

'Nonetheless, the UK's ambition should be to take the lead with CAV in areas where a business case can be made which shows a clear early advantage accruing to the UK' (p. 32)

For its part the Government responds to the Lords' recommendations by echoing and welcoming every acknowledgement of further opportunity while arguing that it is already taking action to address concerns with further research, support for private sector initiatives, or participation in international standard setting. Its response opens by restating the vision that guides its policy:

'The UK has the potential to be a global leader in the development and deployment of automated technologies, building on our heritage as a nation of innovators and entrepreneurs and utilising our existing centres of excellence across numerous sectors' $(98$, p. 1$)$

The Inquiry highlights the supply side challenge of skills shortages. Paul Newman, founder of Oxbotica, a key participant in the CCAV funded trials, is emphatic:

'I cannot overstate the importance of this: we need about 10,000 more engineers a year. We need to plough money into universities to teach information engineering, data engineering and software.' (38, paragraph 16)

The Government responds by claiming 'the UK's supply of specialist skills scores well above the EU average' (p. 4). As with other challenges, a serious issue that suggests Government ambitions might be unrealistic is set aside, and we noted earlier how one contributor reframed this risk as an opportunity to increase the UK's engineering skills.

Reluctance to regulate too soon. Throughout, we observe an aspiration for leadership and the consequent language of a race, in which hesitation risks ceding advantage. This encourages a particular response to the uncertainties inherent in the emergence of the technology: 
'At this time the UK must be careful not to move too quickly to introduce legal or legislative requirements on an industry and sector that is very nascent and developing.' (SmarterUK, 82, paragraph 15.4)

The Government emphasises that it takes safety seriously, but treats other issues as too uncertain to warrant intervention:

'Government recognises that it has a role to play in managing and mitigating any risks that might arise and the importance of striking a balance within the regulatory framework to ensure that laws are in place to prevent harm to humans, while at the same time ensuring that innovation is not stifled and any barriers to the development of these technologies are removed where possible.' (98, paragraph 32)

That this balance is difficult to strike is unavoidable (Collingridge, 1980). The Government's commitment to the supply side and modernising vision for the economy favours a relatively laissez-faire approach. A corollary is to build an optimistic demand side of the imaginary, as one of the Inquiry's own witnesses observes:

'the representation of economic and social benefits in government documents is overly positive and does not reflect the very large uncertainties about many of the potential effects of the widespread adoption of CAV technologies in transport.' (Hopkins, 19, p. 1)

Findings summary. We have shown how the Inquiry material is dominated by voices committed to the building of an AV future (RQ1), endorsing this future as an urgent national project and addressing questions of how to achieve this future (RQ2a). We argue that the effect is to close down debate over the desirability of $\mathrm{AV}$ technology as the best solution to a range of societal challenges, presenting this future as inevitable (RQ2b). Benefits are taken for granted while risks become issues to overcome (RQ2c). Dissenting voices are in the minority and are underrepresented in the Inquiry's overall conclusions. The public are often viewed less as passive agents and more as a hurdle to be overcome, with references to their behaviour deficits as bad drivers, their knowledge deficits in not understanding the technology, and, to the extent they express scepticism, their attitude deficit (RQ2d).

\section{Discussion}

The AV project in the UK. We have treated this House of Lords Inquiry as an exemplar of a number of phenomena proposed by the science and technology studies literature. Following Sovacool and Hess, we have tried to avoid a strict adherence to any one theory of sociotechnical change, emphasising instead the central idea that powerful actors seek to build dominant representations of technological futures, and that these representations can become entrenched, mandating the technological solutions preferred by the authors of those representations. Within the vision of an AV future presented in this Inquiry, we found a number of features proposed by diverse theories, such as the construction of the sociotechnical imaginary as a national project, and the urgency conveyed upon AV technology by framing it as a solution to a Government-defined grand challenge.

Some of our findings corroborate existing research on UK efforts to develop AV technology: the sense of an urgent race (Hopkins and Schwanen, 2018), and the opportunity to reestablish economic strength (Mladenović et al. 2020). In addition, both Hildebrand (2019) and Pangbourne et al. (2020) observe how representations of AV futures present unbalanced analyses of risks and benefits. In this Inquiry, we found more mentions of risks than of benefits, but the risks were typically framed in a positive light, as challenges to address and overcome. Some of the risks are the domains of governance identified in Mladenović et al.'s (2020) analysis of the UK AV imaginary: as we found, substantial issues such as the difficulty of establishing an effective insurance regime or managing cybersecurity risks do not call into question the commitment to $\mathrm{AV}$ technology, but are rather challenges to the regulatory facilitation of the technology. Hopkins notes a further imbalance in written evidence to the Inquiry:

'Anticipated economic benefits such as employment growth, productivity increases, inward investments and GDP growth as well as reductions in road congestion are given greater attention than other grand challenges UK transport and society more generally face-i.e., the need to increase physical activity, improve air quality and reduce greenhouse gas emissions, and concerns over social inequality.' (19, p. 1)

We argue that this criticism is borne out by the Inquiry material with its predominant focus upon how to achieve UK participation in the supply-side of an AV future. The beneficial outcome of achieving 'the other grand challenges' is taken for granted. Progress towards many of these anticipated benefits could actually be made without investment in automation. Targeted public investment in public transportation is key to increased accessibility and to address social inequalities (Di Ciommo and Shiftan, 2017) and improve sustainability (McLeod et al., 2017). Such public goods require Government intervention, in particular to manage the balance between private and public transportation (see Cohen and Cavoli, 2019). As Pangbourne et al. (2020) note, the commercial imperatives of new mobility solutions may well increase travel and actually worsen transport's negative externalities. The Inquiry report does note the need for 'the right policy decisions' regarding such public goods, but puts greater emphasis on regulatory steps to facilitate AV technology in the UK in pursuit of the economic opportunity. We think it reasonable to question whether automation per se will deliver policy interventions lacking in the past. Currie (2018) protests forcefully that the rhetoric extolling the sharing economy associated with visions of an AV future tends to forget that we can achieve the same benefits from the existing shared economy of public transportation.

Hildebrand (2019) reveals how AV promotion focuses on positive corporate visions of what she calls the technological sublime: some of the Inquiry's contributors go much further, imagining not just the emancipation of individual travellers but a wholesale re-engineering of society, 'rebalancing the economy' and '[shifting] how we view public and private transport', whereby the technological solution delivers the aspirations of the grand challenges.

The Inquiry and the Public. The Inquiry seeks to achieve a social appraisal of technology. There have been many calls to open up and democratise sociotechnical change generally (Stilgoe et al. 2013; Stirling, 2008) as well as in relation to new mobility technology:

"there is a need to engage transparently all relevant societal constituencies in critical conversations and decisionmaking about [traffic control] technology development" (Mladenovic and McPherson, 2016, p. 1145).

The Inquiry frequently mentions public consultation, but the corpus itself sees little representation of public views. The science 
and technology studies literature has problematised the public deliberation it has called for (Irwin, 2006). We noted earlier the risk that public inquiries can become performances to legitimate the sociotechnical project that powerful actors are pursuing. The remit of the Inquiry, the nature of its contributors, and its restricted focus on how to achieve an AV future as the already chosen solution to broader mobility challenges all deliver such a performance. As one member of the Lords notes, the result is a rather un-self-critical recitation of the desirability of the $\mathrm{AV}$ future, which he likened to the rattling of tambourines by cult members.

Conventional vehicles and AVs both have many publics: people can be pedestrians or drivers, accident victims or consumers. Graf and Sonnberger (2019) and Mladenović et al. (2020) both argue that in representations of an AV future the public are construed as users rather than citizen co-producers of that future. But the marginalisation of the public from a constructive role starts much earlier. The foundational premise for promoting AVs, rehearsed many times in the Inquiry, is road safety, a frame in which the public are either passive victims or dangerous drivers. The automotive industry has long laid the blame for accidents firmly upon fallible human drivers (Nader, 1973), just as the human operator tends to be blamed when any automated system fails (Leveson, 2011). The foundational hostility to the driver is just one example of the way the evidence in the Lords Inquiry frequently paints the public as deficient: deficient as bad drivers generally, or potentially as drivers impeding CAVs, deficient as consumers ignorant of the benefits of the new technology, sometimes deficient in having Luddite fears of the new technology. This does not form the basis for an effective co-production between competing interest groups of the technology as it emerges. Instead, a vision structured by supplyside aspirations chooses to let the technology determine the future social shape of transportation, denying public agency in shaping future mobility (see Jasanoff, 2015 on imaginaries and agency). Rather than opening up the project to debate, the Inquiry is itself a part of the project, marginalising dissent and alternative visions. However, the practicalities of integrating AVs with other road users even in restricted spaces may demand the involvement, and cooperation, of the public, creating opportunities for a more substantive role for public engagement.

\section{Conclusion}

We argue that the case study of the Lords' AV Inquiry exhibits many of the features attributed to representations of sociotechnical futures by the science and technology studies literature. The Inquiry process itself manifests the collaboration between heterogeneous actors to build a representation of the future framed as a national project, presenting it as desirable and inevitable. Posed as a technological solution to grand challenges, delivering an $\mathrm{AV}$ future in which the $\mathrm{UK}$ is an active participant becomes an end in itself rather than just an instrument to achieve the policy objectives expressed in the challenges. The Inquiry reinforces the Governmental prioritisation of UK participation in the supply side of the AV future. The demand-side of the future receives less attention, with the public construed as future users whose concerns are set aside for the moment. The Inquiry frequently represents the public as deficient, whether as bad drivers, as unfamiliar with the technology or as misguided in their fears of this future. We argue that construing the public as deficient encourages their exclusion from shaping future mobility systems. The genuine engagement many call for to address societal grand challenges requires greater confidence in the constructive role the public can play.

\section{Data availability}

As explained in the paper, all data analysed in this article are freely available from the House of Lords https:// old.parliament.uk/business/committees/committees-a-z/lordsselect/science-and-technology-committee/inquiries/parliament2015/autonomous-vehicles/ and https://www.parliament.uk/ globalassets/documents/lords-committees/science-technology/ autonomous-vehicles/Autonomous-vehicles-evidence.pdf

Received: 10 June 2020; Accepted: 4 May 2021;

Published online: 02 September 2021

\section{Notes}

1 Except where specifically identified we will treat the terms Connected and Autonomous Vehicle, Autonomous Vehicle, Automated Vehicle and Driverless Car as interchangeable. This is a simplification; debate continues over what 'AVs' should be called (Shladover, 2017).

2 Written submissions were made by 85 contributors and 3 made supplementary submissions, totalling 88 written submissions.

3 Brief information on the conduct of the committee is described on p16 of the final report (House of Lords Science and Technology Select Committee, 2017). We confirmed details in correspondence with the Clerk to the Committee, Anna Murphy.

4 At 30 January 2020, http://www.parliament.uk/autonomous-vehicles

5 The codebook comprises 64 codes. One code was added after assessing intercoder reliability.

6 HMG refers to 'Her Majesty's Government'. Government refers to Ministers or civil servants working directly within ministerial departments. HMG non-departmental refers to government executive entities such as the Meteorological Office. HMG Affiliated R\&D refers to research organisations which are closely affiliated to government, in contrast to those based within academic institutions or commercial organisations such as management consultancies.

7 Supplementary table S3 provides the full version of the information presented in Figs. 1 and 2, including head codes, sub-head codes and individual specific codes.

8 We explained above the generation of the catch-all 'unspecified' subcodes within each major theme. These are excluded from the analysis in Fig. 2 because they cover a number of ideas and their consequent heterogeneity makes them less informative. For example, 'public unspecified' includes references to the public as employees and also as accident victims.

9 References to documents in the corpus are given as: abbreviated name of the witness, 'AUV' document number as listed in Supplementary Table S1, and a paragraph or page reference. In the case of the oral evidence sessions the reference is to the question number. Documents available, as at 30 January 2020, at http://www.parliament.uk/ autonomous-vehicles

10 The attribution of this quote is apocryphal (Vlaskovits, 2011).

\section{References}

Akrich M (1992) The de-scription of technical objects. In: Bijker WE, Law J (Eds.) Shaping technology/building society: studies in sociotechnical change. MIT Press, Cambridge

Bainbridge L (1983) Ironies of automation. Automatica 19(6):775-779. https:// doi.org/10.1016/0005-1098(83)90046-8

Bauer M (2000) Classical content analysis: a review. In: Bauer M, Gaskell G (Eds.) Qualitative researching with image, text and sound. Sage, London, pp. 131-151

Bauer M, Gaskell G (1999) Towards a paradigm for research on social representations. J Theory Soc Behav 29(2):163-186. https://doi.org/10.1111/14685914.00096

Bauer M, Gaskell G (2008) Social representations theory: a progressive research programme for social psychology. J Theory Soc Behav 38(4):335-353. https:// doi.org/10.1111/j.1468-5914.2008.00374.x

Bergman N, Schwanen T, Sovacool BK (2017) Imagined people, behaviour and future mobility: insights from visions of electric vehicles and car clubs in the United Kingdom. Transp Policy 59:165-173. https://doi.org/10.1016/ j.tranpol.2017.07.016

Braun R, Randell R (2020) Futuramas of the present: the "driver problem" in the autonomous vehicle sociotechnical imaginary. Humanit Soc Sci Commun 7(1):163. https://doi.org/10.1057/s41599-020-00655-z

BSI, \& Transport Systems Catapult (2017) Connected and autonomous vehicles. A UK standards strategy. Summary report. https://s3-eu-west1.amazonaws.com/media.ts.catapult/wp-content/uploads/2016/03/23141343/ CAV-standards-strategy-summary-report.pdf 
Burns L, Shulgan C (2018) Autonomy: the quest to build a driverlesscar - and how it will reshape our world. Collins, London

Centre for Connected and Autonomous Vehicles (2016). Pathway to driverless cars: proposals to support advanced driver assistance systems and automated vehicle technologies. Retrieved from London: https://www.gov.uk/ government/uploads/system/uploads/attachment_data/file/536365/ driverless-cars-proposals-for-adas-and_avts.pdf

Centre for Connected and Autonomous Vehicles. (2017) UK testing ecosystem for connected and autonomous vehcles: government response to the call for evidence. Retrieved from London: https://www.gov.uk/government/ consultations/driverless-vehicle-testing-facilities-call-for-evidence

Cohen T, Cavoli C (2019) Automated vehicles: exploring possible consequences of government (non)intervention for congestion and accessibility. Transp Rev 39(1):129-151. https://doi.org/10.1080/01441647.2018.1524401

Cohen T, Jones P, Cavoli C, Phillips B (2017). Social and behavioural questions associated with automated vehicles: a literature review. Retrieved from London: https://www.gov.uk/government/publications/social-andbehavioural-questions-associated-with-automated-vehicles

Collingridge D (1980) The social control of technology. Frances Pinter, London

Currie G (2018) Lies, damned lies, avs, shared mobility, and urban transit futures. J Public Transp 21(1):19-30

Department for Business Skills and Innovation, \& Department for Transport (2015) UK to lead development of driverless car technology.

Department for Transport (2015a) Code of practice for testing of automated vehicle technologies. https://www.gov.uk/government/publications/ automated-vehicle-technologies-testing-code-of-practice

Department for Transport (2015b) The pathway to driverless cars: a detailed review of regulations for automated vehicle technologies. Retrieved from London: https://www.gov.uk/government/publications/driverless-cars-in-the-uk-aregulatory-review

Department for Transport, \& Jones A (2016) Driverless cars are the future, not science fiction. https://www.gov.uk/government/speeches/driverless-cars-arethe-future-not-science-fiction

Di Ciommo F, Shiftan Y (2017) Transport equity analysis. Transp Rev 37(2):139-151. https://doi.org/10.1080/01441647.2017.1278647

Ely A, van Zwanenberg P, Stirling A (2014) Broadening out and opening up technology assessment: approaches to enhance international development, co-ordination and democratisation. Res. Policy 43(3):505-518

Engels F, Wentland A, Pfotenhauer SM (2019) Testing future societies? Developing a framework for test beds and living labs as instruments of innovation governance. Res Policy 48(9):103826. https://doi.org/10.1016/j.respol.2019.103826

European Commission (2015) Special Eurobarometer 427: autonomous systems. http://ec.europa.eu/commfrontoffice/publicopinion/archives/ebs/ ebs_427_en.pdf

European Commission (2020) Special Eurobarometer 496: expectations and concerns of connected and automated driving. https://ec.europa.eu/ commfrontoffice/publicopinion/index.cfm/Survey/getSurveyDetail/search/ 496/surveyKy/2231

Farr RM, Moscovici S (1984) Social representations. Cambridge University Press, Cambridge

Flink T, Kaldewey D (2018) The new production of legitimacy: STI policy discourses beyond the contract metaphor. Res Policy 47(1):14-22. https:// doi.org/10.1016/j.respol.2017.09.008

Graf A, Sonnberger M (2019) Responsibility, rationality, and acceptance: How future users of autonomous driving are constructed in stakeholders' sociotechnical imaginaries. Public Underst Sci 29(1):61-75. https://doi.org/ $10.1177 / 0963662519885550$

Gwet KL (2008) Computing inter-rater reliability and its variance in the presence of high agreement. Br J Math Stat Psychol 61(1):29-48. https://doi.org/ $10.1348 / 000711006$ X126600

Haugland BT, Skjølsvold TM (2020) Promise of the obsolete: expectations for and experiments with self-driving vehicles in Norway. Sustainability 16(1):37-47. https://doi.org/10.1080/15487733.2020.1765677

Hildebrand JM (2019) On self-driving cars as a technological sublime. Techné 23(2):153-173

Hilgartner S (2015) Capturing the imaginary: vanguards, visions and the synthetic biology revolution. In: Hilgartner S, Miller C, Hagendijk R (Eds.) Science and democracy. Routledge, London, pp. 33-55

HM Government. (2017) Industrial strategy: building a Britain fit for the future. Retrieved from London: https://www.gov.uk/government/publications/ industrial-strategy-building-a-britain-fit-for-the-future

HM Treasury (2013) National Infrastructure Plan 2013. Retrieved from London: https://www.gov.uk/government/publications/national-infrastructure-plan2013

Hopkins D, Schwanen T (2018) Automated mobility transitions: governing processes in the UK. Sustainability 10(4). https://doi.org/10.3390/su10040956

Hottentot C, Meines V, Pinckaers M (2015) Experiments on autonomous and automated driving: an overview 2015. Retrieved from The Hague: https:// www.anwb.nl/binaries/content/assets/anwb/pdf/over-anwb/persdienst/ rapport_inventarisatie_zelfrijdende_auto.pdf

House of Lords Science and Technology Select Committee (2016) Autonomous vehicles: call for evidence. https://www.parliament.uk/documents/lordscommittees/science-technology/autonomous-vehicles/CfE-autonomousvehicles-FINAL.pdf

House of Lords Science and Technology Select Committee (2017) Connected and autonomus vehicles: the future? Retrieved from https:// publications.parliament.uk/pa/ld201617/ldselect/ldsctech/115/115.pdf

Irwin A (2006) The politics of talk. Soc Stud Sci 36(2):299-320. https://doi.org/ $10.1177 / 0306312706053350$

Jasanoff S (2015) Future imperfect: science, technology and the imaginations of modernity. In: Jasanoff S, Kim S-H (Eds.) Dreamscapes of modernity: sociotechnical imaginaries and the fabrication of power. The University of Chicago Press, London, pp. 1-33

Jasanoff S, Kim S-H (2009) Containing the atom: sociotechnical imaginaries and nuclear power in the United States and South Korea. Minerva 47(2):119. https://doi.org/10.1007/s11024-009-9124-4

Kaldewey D (2018) The grand challenges discourse: transforming identity work in science and science policy. Minerva 56(2):161-182. https://doi.org/10.1007/ s11024-017-9332-2

Krippendorff K (2004) Content analysis: an introduction to its methodology. Sage, Thousand Oaks

Kuhlmann S, Rip A (2018) Next-generation innovation policy and grand challenges. Sci Public Policy 45(4):448-454. https://doi.org/10.1093/scipol/scy011

Leveson N (2011) Applying systems thinking to analyze and learn from events. Saf Sci 49(1):55-64. https://doi.org/10.1016/j.ssci.2009.12.021

Manderscheid K (2018) From the auto-mobile to the driven subject? Transfers 8(1):24-43. https://doi.org/10.3167/TRANS.2018.080104

McGoogan C (2016) 'You're killing people': Elon Musk attacks critics of selfdriving cars. The Telegraph. http://www.telegraph.co.uk/technology/2016/10/ 20/youre-killing-people-elon-musk-attacks-critics-of-self-driving-c/

McLeod S, Scheurer J, Curtis C (2017) Urban public transport: planning principles and emerging practice. J Plan Lit 32(3):223-239. https://doi.org/10.1177/ 0885412217693570

Mladenovic MN, McPherson T (2016) Engineering social justice into traffic control for self-driving vehicles? Sci Eng Ethics 22(4):1131-1149. https://doi.org/ 10.1007/s11948-015-9690-9

Mladenović MN, Stead D, Milakis D, Pangbourne K, Givoni M (2020) Governance cultures and sociotechnical imaginaries of self-driving vehicle technology: comparative analysis of Finland, UK and Germany. Academic Press

Moscovici S (1984) The Phenomenon of Social Representations. In R. M. Farr \& S. Moscovici (Eds), Social Representations (pp. 3-69). Cambridge: Camridge University Press

Nader R (1973) Unsafe at any speed: the designed-in dangers of the American automobile (Expanded edn.). Bantam, London

Norton PD (2008) Fighting traffic: the dawn of the motor age in the American city. MIT Press, Cambridge

Pangbourne K, Mladenović MN, Stead D, Milakis D (2020) Questioning mobility as a service: unanticipated implications for society and governance. Transp Res Part A 131:35-49. https://doi.org/10.1016/j.tra.2019.09.033

Riffe D, Lacy S, Fico F, Watson B (2019) Analyzing media messages. Routledge, New York

Rough E (2011) Policy learning through public inquiries? The case of UK nuclear energy policy 1955-61. Environ Plan C 29(1):24-45. https://doi.org/10.1068/ c09184

Savaget P, Acero L (2017) Plurality in understandings of innovation, sociotechnical progress and sustainable development: an analysis of OECD expert narratives. Public Underst Sci https://doi.org/10.1177/0963662517695056.

Shladover SE (2017) Connected and automated vehicle systems: introduction and overview. J Intell Transp Syst 1-11. https://doi.org/10.1080/ 15472450.2017.1336053

Smallman M (2019) 'Nothing to do with the science': How an elite sociotechnical imaginary cements policy resistance to public perspectives on science and technology through the machinery of government. Soc Stud Sci 50(4):589-608. https://doi.org/10.1177/0306312719879768

Solon O (2018) Who's driving? Autonomous cars may be entering the most dangerous phase. The Guardian. https://www.theguardian.com/technology/ 2018/jan/24/self-driving-cars-dangerous-period-false-security

Sovacool BK, Hess DJ (2017) Ordering theories: typologies and conceptual frameworks for sociotechnical change. Soc Stud Sci 47(5):703-750. https:// doi.org/10.1177/0306312717709363

Sparrow R, Howard M (2017) When human beings are like drunk robots: driverless vehicles, ethics, and the future of transport. Transp Res Part C 80:206-215. https://doi.org/10.1016/j.trc.2017.04.014

Stilgoe J, Lock S, Wilsdon J (2014) Why should we promote public engagement with science? Public Underst Sci 23(1):4-15. https://doi.org/10.1177/ 0963662513518154 
Stilgoe J, Owen R, Macnaghten P (2013) Developing a framework for responsible innovation. Res Policy 42(9):1568-1580. https://doi.org/10.1016/ j.respol.2013.05.008

Stirling A (2008) "Opening up" and "Closing down": power, participation, and pluralism in the social appraisal of technology. Sci Technol Hum Values 33(2), 262-294. http://www.jstor.org/stable/29734034

Sturgis P, Allum N (2004) Science in society: re-evaluating the deficit model of public attitudes. Public Underst Sci 13:55-74

Tennant C, Stares S, Howard S (2019) Public discomfort at the prospect of autonomous vehicles: building on previous surveys to measure attitudes in 11 countries. Transp Res Part F 64:98-118. https://doi.org/10.1016/j.trf.2019.04.017

The Economist (2016) Uberworld: the world's most valuable startup is leading the race to transform the future of transport. The Economist. Retrieved from https://www.economist.com/leaders/2016/09/03/uberworld

The Economist (2018) A different world: self-driving cars will profoundly change the way people live. The Economist. Retrieved from https://www.economist.com/ special-report/2018/03/01/self-driving-cars-will-profoundly-change-the-waypeople-live

Transport Systems Catapult (2017) Market forecast for connected and autonomous vehicles. Retrieved from Milton Keynes: https://s3-eu-west1.amazonaws.com/media.ts.catapult/wp-content/uploads/2017/09/08094421/ 15780_TSC_Market_Forecast_for_CAV_Report_FINAL.pdf

U.S. Department of Transportation (2016) Federal automated vehicles policy: accelerating the next revolution in roadway safety. https://www.transportation.gov/ AV/federal-automated-vehicles-policy-september-2016

U.S. Department of Transportation (2017) Beyond Traffic 2045. Retrieved from https:// www.transportation.gov/policy-initiatives/beyond-traffic-2045-final-report

van Loon J (2002) Risk and technological culture: towards a sociology of virulence. Routledge, New York

Vlaskovits P (2011) Henry Ford, innovation, and that "faster horse" quote. https:// hbr.org/2011/08/henry-ford-never-said-the-fast

Welsh I, Wynne B (2013) Science, scientism and imaginaries of publics in the UK: passive objects, incipient threats. Sci Cult 22(4):540-566

Wongpakaran N, Wongpakaran T, Wedding D, Gwet KL (2013) A comparison of Cohen's Kappa and Gwet's ACl when calculating inter-rater reliability coefficients: a study conducted with personality disorder samples. BMC Med Res Methodol 13(1):61. https://doi.org/10.1186/1471-2288-13-61

\section{Acknowledgements}

During the writing up phase of this paper Tennant's time was funded by the UK Economic and Social Research Council (ESRC) funded project, Driverless Futures?, grant ES/ S001832/1.

\section{Competing interests}

The authors declare no competing interests.

\section{Additional information}

Supplementary information The online version contains supplementary material available at https://doi.org/10.1057/s41599-021-00882-y.

Correspondence and requests for materials should be addressed to C.T.

Reprints and permission information is available at http://www.nature.com/reprints

Publisher's note Springer Nature remains neutral with regard to jurisdictional claims in published maps and institutional affiliations.

\begin{abstract}
(c) Open Access This article is licensed under a Creative Commons Attribution 4.0 International License, which permits use, sharing, adaptation, distribution and reproduction in any medium or format, as long as you give appropriate credit to the original author(s) and the source, provide a link to the Creative Commons license, and indicate if changes were made. The images or other third party material in this article are included in the article's Creative Commons license, unless indicated otherwise in a credit line to the material. If material is not included in the article's Creative Commons license and your intended use is not permitted by statutory regulation or exceeds the permitted use, you will need to obtain permission directly from the copyright holder. To view a copy of this license, visit http://creativecommons.org/ licenses/by/4.0/.
\end{abstract}

(C) The Author(s) 2021 